\title{
IMPLEMENTASI DAN PERANCANGAN PENGUKUR TINGGI BADAN MENGGUNAKAN SENSOR ULTRASONIK
}

\author{
Mochammad Yusa ${ }^{1}$, Joko Dwi Santoso ${ }^{2}$, Andi Sanjaya ${ }^{3}$ \\ ${ }^{1}$ Informatika/Fakultas Teknik, Universitas Bengkulu, Jl. Wr. Supratman, Kandang Limun, Kec. Muara Bangka Hulu, \\ Sumatera, Bengkulu \\ ${ }^{2}$ Teknik Komputer / Ilmu Komputer, Universitas AMIKOM Yogyakarta, Jl. Ring Road Utara, Condong Catur, \\ Sleman, Yogyakarta \\ ${ }^{3}$ Sistem Informasi/Fakultas Teknik Informatika, Universitas Potensi Utama, JL. KL. Yos Sudarso Km. 6,5 No. 3-A, \\ Tanjung Mulia, Tj. Mulia, Kec. Medan Deli, Kota Medan, Sumatera Utara \\ mochammad.yusa@unib.ac.id ${ }^{1}$, joko@amikom.ac.id ${ }^{2}$, andi@potensi-utama.ac.id ${ }^{3}$
}

\begin{abstract}
Abstrak - Untuk mengukur ketinggian manusia secara umum masih dilakukan secara manual dengan menggunakan meteran. Jika kita hanya ingin satu atau tiga orang mungkin tidak menjadi masalah, tetapi jika kita ingin mengukur jumlah lebih dari 50 orang bahkan ratusan orang, itu akan sangat merepotkan dan menghabiskan banyak waktu. Dengan memanfaatkan kemajuan teknologi informasi dan komunikasi di era sekarang ini, maka muncul ide untuk membuat alat yang dapat mengukur tinggi manusia secara otomatis yang dapat mempermudah dan mempercepat manusia dalam melakukan pengukuran ketinggian. Tujuan dari penelitian ini adalah untuk merancang alat yang dapat mengukur tinggi manusia secara otomatis dengan tampilan digital. Hasil pengujian menunjukkan bahwa alat ini bekerja sesuai dengan desain, yang jika manusia memanjat alat ini, alat tersebut tidak akan secara langsung mengukur ketinggian secara otomatis, dan hasilnya akan ditampilkan pada LCD.
\end{abstract}

Kata Kunci: Height, Arduino Uno, Ultrasonic Sensors, LCD.

Abstract - To measure the height of man in general is still done manually by using the meter. If we want to just one or three people might not be a problem, but if we want to measure the amount of more than 50 people even hundreds of people, it would be very inconvenient and spent a lot of time. By utilizing the advancement of information and communication technology in today's era, then came the idea to create a tool that can measure the human height automatically that could simplify and accelerate human in performing the height measurement. The purpose of this study was to design a tool that can measure the human height automatically with a digital display. The test results show that it works in accordance with the design, which if man climbs this tool, the tool will not directly measure the height automatically, and the results will be displayed on the LCD.

Keywords - Height, Arduino Uno, Ultrasonic Sensors, LCD.

\section{PENDAHULUAN}

Semakin berkembangnya teknologi baik di bidang pendidikan maupun industri maka meningkat pula daya pikir manusia akan teknologi sebagai kebutuhan. Dari perkembangan tersebut tentunya muncul teknologi-teknologi baru yang dapat mengurangi beban tenaga manusia dalam hal mengerjakan aktifitas atau pekerjaannya.

Pengukuran tinggi badan biasanya dilakukan secara manual yaitu dengan menggunakan meteran. Apabila yang ingin kita ukur hanya satu atau tiga orang mungkin tidak menjadi permasalahan, akan tetapi apabila yang kita ukur jumlahnya lebih dari 50 orang bahkan ratusan orang seperti kasus dalam suatu tes kesehatan yang dilakukan oleh suatu instansi dalam penerimaan 
Jurnal Pseudocode, Volume VIII Nomor 1, Februari 2021, ISSN 2355-5920, e-ISSN 2655-1845 www.ejournal.unib.ac.id/index.php/pseudocode

pegawai baru, hal ini tentunya akan sangat merepotkan dan banyak menghabiskan waktu.

Dengan adanya teknologi mikrokontroler, dapat digunakan membuat alat otomatis yang bisa mempermudah dan mempercepat manusia dalam mengerjakan aktifitasnya contohnya membuat alat pengukur tinggi badan otomatis. Dengan adanya alat ini diharapkan dapat melakukan pengukuran secara cepat sehingga mempermudah pekerjaan dan menghemat waktu dalam pengukuran tinggi badan dengan hasil yang akurat.

Berdasarkan uraian di atas, maka perumusan masalah yang didapatkan adalah sebagai berikut: Bagaimana merancang alat ukur tinggi badan otomatis dengan sensor ultrasonik SRF-05 berbasis mikrokontroler?.

\section{LANDASAN TEORI}

\section{A. Mikrokontroler}

Mikrokontroler adalah sistem computer yang seluruh atau sebagian besar elemennya dikemas dalam satu chip IC sehingga sering juga di sebut dengan single chip microcomputer. Rangkain mikrokontroler tersusun atas sebuah IC (Intergrated Circuit) dan beberapa komponen pendukung sehingga bisa bekerja dengan baik.

Mikrokontoler merupakan suatu trobosan teknologi mikroprosesor dan mikrokomputer terbaru yang hadir memenuhi kebutuhan pasar. Sebagai teknologi terbaru dengan semikonduktor yang mengandung transistor yang lebih banyak namun hanya membutuhkan ruang kecil sebagai wadah penempatannya dan dapat diproduksi secara massal sehingga harganya lebih murah dan dapat terjangkau oleh hampir seluruh kalangan masyarakat. Oleh karena itu mikrokontroler sangan cocok diterapkan untuk mengontrol berbagai peralatan-peralatan yang lebih canggih dibandingkan dengan computer PC, karena efektivitas dan kefleksibelannya yang tinggi [4].

B. Arduino

Arduino merupakan platform rangkaian alat elektronik yang bersifat open-source, dimana perangkat keras dan perangkat lunaknya fleksibel dan bebas untuk dimodifikasi. Arduino ditujukan bagi para seniman, desainer, dan siapapun yang tertarik dalam menciptakan objek atau lingkungan yang interaktif.

Arduino pada awalnya dikembangkan di Ivrea, Italia. Nama Arduino adalah sebuah nama maskulin yang berarti teman yang kuat. Platform Arduino terdiri dari Arduino board, shield, bahasa pemrograman Arduino, dan Arduino development environment. Arduino board biasanya memiliki sebuah chip dasar mikrokontroler Atmel AVR ATmega8 [5].

Bahasa pemrograman Arduino adalah bahasa pemrograman yang umum digunakan untuk membuat perangkat lunak yang ditanamkan pada Arduino board. Bahasa pemrograman Arduino mirip dengan bahasa pemrograman $\mathrm{C}++$.

\section{Arduino Uno}

Arduino uno adalah Arduino board yang menggunakan mikrokontroler ATmega328. Arduino uno memiliki 14 pin digital (6 pin dapat digunakan sebagai output PWM), 6 input analog, sebuah $16 \mathrm{MHz}$ osilator kristal, sebuah koneksi USB, sebuah konektor sumber tegangan, sebuah header ICSP, dan sebuah tombol reset.

Arduino uno memuat segala hal yang dibutuhkan untuk mendukung sebuah mikrokontroler. Hanya dengan menghubungkannya ke sebuah komputer melalui USB atau memberikan tegangan DC dari baterai atau adaptor AC ke DC sudah dapat membuanya 
Jurnal Pseudocode, Volume VIII Nomor 1, Februari 2021, ISSN 2355-5920, e-ISSN 2655-1845

www.ejournal.unib.ac.id/index.php/pseudocode

bekerja. Arduino uno menggunakan ATmega16U2 yang diprogram sebagai USB-to-serial converter untuk komunikasi serial ke komputer melalui port USB [5].

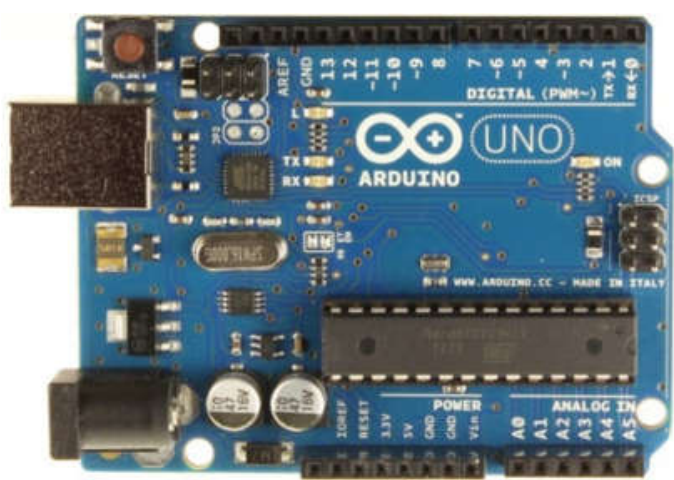

Gambar 1. Arduino Uno

\section{Sensor Ultrasonik HY-SRF05}

Sensor ultrasonik adalah sensor yang bekerja berdasarkan prinsip pantulan gelombang dimana sensor menghasilkan gelombang pantulan ke benda yang kemudian menangkapnya kembali dengan perbedaan waktu sebagai dasar perhitungannya.

Perbedaan waktu antara gelombang pantulan yang di kembalikan dan yang diterima kembali adalah berbanding lurus dengan jarak atau tinggi objek yang memantulkannya. Jenis objek yang dapat di indranya adalah padat, cair dan butiran. Tanpa kontak jarak $3 \mathrm{~cm}$ sampai 4 meter dan dapat dengan mudah dihubungkan dengan mikrokontroler malalui satu pin I/O saja.Dimensi : $2,6 \mathrm{~cm}(\mathrm{p}) \times 4,1 \mathrm{~cm}(1) \times 6,2 \mathrm{~cm}(\mathrm{t})[6]$.

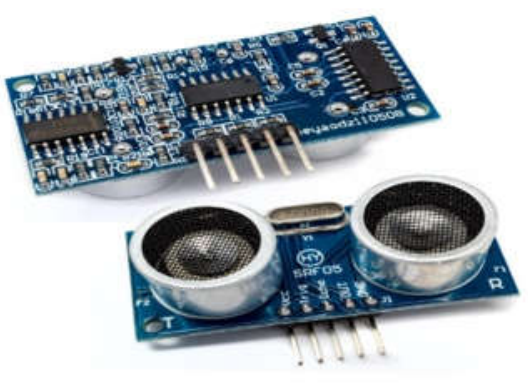

Gambar 2 Sensor Ultrasonik

\section{Spesifikasi Dari Sensor Ultrasonik}

Adapun spesifikasi dari sensor ultrasonik srf 05 dengan spesifikasi sebagai berikut antara lain :

1. Memiliki 2 jenis antarmuka yang dapat aktif bersamaan, yaitu I2C-bus (fSCL maks. $65 \mathrm{kHz}$ ) dan pulse width $(10 \mu \mathrm{s} / \mathrm{mm})$.

2. 8 modul dapat digunakan bersama dalam satu sistem I2C-bus yang hanya membutuhkan 2 pin I/O mikrokontroler saja.

3. Membutuhkan catu daya tunggal +5 VDC, dengan konsumsi arus $17 \mathrm{~mA}$ typ. (tanpa sensor infrared ranger).

4. Bekerja pada tegangan DC 5 volt.

5. Beban arus sebesar $30 \mathrm{~mA}-50 \mathrm{~mA}$.

6. Menghasilkan gelombang dengan frekuensi 40 $\mathrm{KHz}$.

7. Jangkauan jarak yang dapat dideteksi $3 \mathrm{~cm} \mathrm{-}$ $400 \mathrm{~cm}$

8. Membutuhkan trigger input minimal sebesar 10 uS.

9. Dapat digunakan dalam dua pilihan mode yaitu input trigger dan output echo terpasang pada pin yang berbeda atau input trgger dan output echo terpasang dalam satu pin yang sama.

\section{Cara Kerja Sensor Ultrasonik}

Cara kerja sensor ultrasonik dengan cara memantulkan gelombang ke sebuah objek kemudian data yang dipantulkan menentukan jarak dari sensor ke objek.

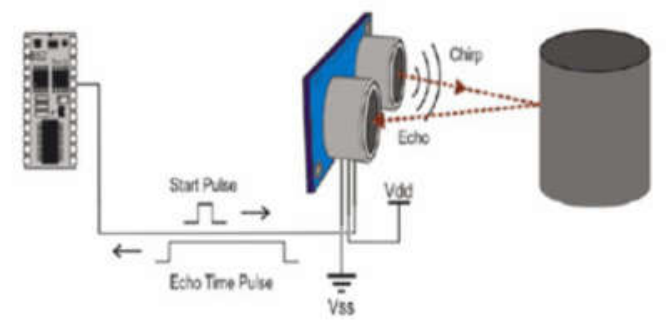

Gambar 3 Cara Kerja Sensor Ultrasonik 
Jurnal Pseudocode, Volume VIII Nomor 1, Februari 2021, ISSN 2355-5920, e-ISSN 2655-1845

www.ejournal.unib.ac.id/index.php/pseudocode

D. LCD (Liquid Crystal Display)

LCD (Liquid Crystal Display) sering diartikan dalam bahasa indonesia sebagai tampilan kristal cair merupakan suatu jenis media tampilan yang menggunakan kristal cair sebagai penampil utama. LCD dapat menampilkan karakter ASCI sehingga kita bisa menampilkan campuran huruf dan angka sekaligus berwarna ataupun tidak berwarna, hal ini disebabkan karena terdapat banyak sekali titik cahaya (piksel) yang terdiri dari satu buah kristal cair sebagai sebuah titik cahaya. Walaupun disebut sebagai titik cahaya, namun kristal cair ini tidak memancarkan cahaya sendiri. Sumber cahaya didalam sebuah perangkat LCD adalah lampu neon berwarna putih dibagian belakang susunan kristal cair tadi.

Titik cahaya yang jumlahnya puluhan ribu bahkan jutaan inilah yang membentuk tampilan citra. Kutub kristal cair yang dilewati arus listrik akan berubah karena pengaruh polarisasi medan magnetik yang timbul dan oleh karenanya akan hanya membiarkan beberapa warna diteruskan sedangkan warna lainnya tersaring.

Dalam menampilkan karakter untuk membantu menginformasikan proses dan control yang terjadi dalam suatu program robot, kita sering menggunakan LCD. Salah satu LCD yang sering dipergunakan adalah LCD $16 \times 4$, artinya LCD tersebut terdiri dari 16 kolom dan 4 baris. LCD ini sering digunakan karena harganya yang relatif murah dan pemakaianya cukup mudah. LCD yang kita gunakan masih membutuhkan agar dapat dikoneksikan dengan system minimum dalam suatu mikrokontroler. Driver tersebut berisi rangkaian pengaman, pengatur tingkat kecerahan backligt maupun data serta untuk mempermudah pemasangan di mikrokontroler.

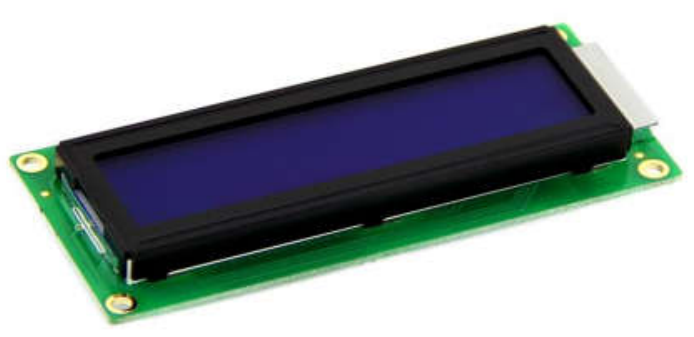

Gambar 4. LCD $16 \times 4$

\section{ANALISIS DAN PERANCANGAN}

A. Alat dan Bahan Penelitian

Alat dan bahan yang diperlukan untuk Perancangan Alat Ukur Tinggi Badan Otomatis dengan menggunakan Sensor Ultrasonik SRF-05 Berbasis Arduino Uno R3 berupa komponen perangkat lunak dan perangkat keras. Perangkat keras yang digunakan meliputi komponen pembangun mikrokontroler Arduino uno, sedangkan perangkat lunak yang diperlukan mempunyai kebutuhan sebagai sistem pendukung perancangan Perancangan Alat Ukur Tinggi Badan Otomatis. Alat penelitian yang di perlukan antara lain :

\section{Perangkat keras}

Dalam Perancangan Alat Ukur Tinggi Badan Otomatis Berbasis Mikrokontroler memerlukan beberapa perangkat keras sebagai berikut :

\section{Arduino Uno}

Papan Arduino uno berfungsi sebagai pengendali utama dari keseluruhan sistem atau bisa disebut sebagai otak sistem. Rangkaian ini dilengkapi dengan port-port dimana dapat berfungsi untuk menghubungkan alat elektronik lainnya seperti sensor srf 05 dan lcd mengunakan kabel jumper, selain itu papan Arduino uno r3 tersebut mempunyai beberapa jenis memori dengan fungsi yang berbeda-beda, salah satunya berfingsi untuk menyimpan kode program. 
Jurnal Pseudocode, Volume VIII Nomor 1, Februari 2021, ISSN 2355-5920, e-ISSN 2655-1845 www.ejournal.unib.ac.id/index.php/pseudocode

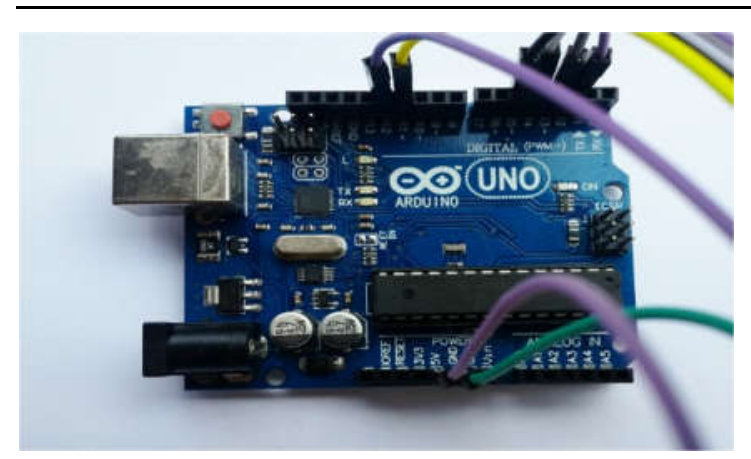

Gambar 5. Board Arduino Uno

\section{LCD (Liquid Crystal Display)}

Berfungsi sebagai output atau tampilan data dari hasil yang telah diproses oleh mikrokontroler.

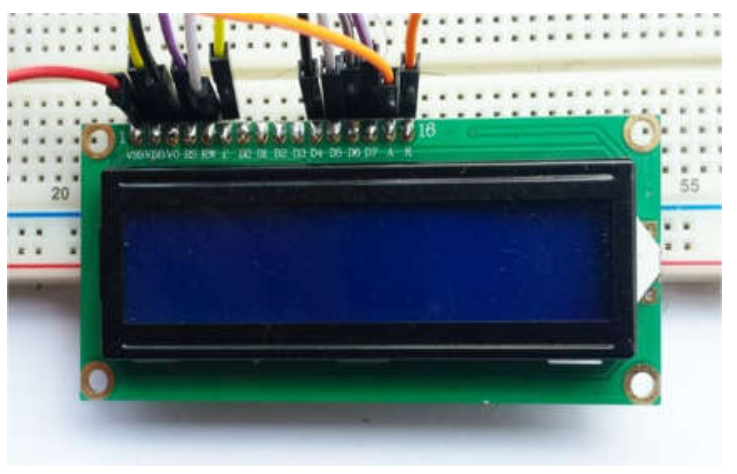

Gambar 6. LCD 16x2

3. Sensor Ultrasonik HY-SRF05

Sensor ultrasonik digunakan sebagai sensor jarak dalam mengukur tinggi air pada evaporimeter. Rangkaian yang terdiri dari TX (transmitter) dan RX (receiver). TX berfungsi sebagai pemancar sinyal yang mengenai penghalang sedangkan RX berfungsi sebagai penerima sinyal pantulan dari TX.

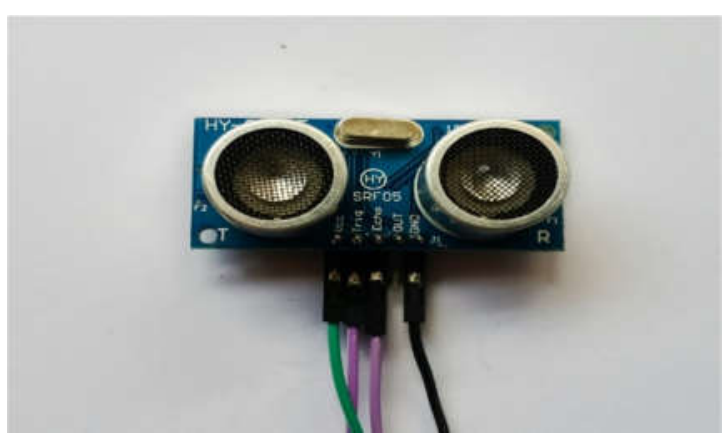

Gambar 7. Sensor Ultrasonik HY-SRF05

\section{USB Connection Type B}

USB Connection type $\mathrm{B}$ berfungsi sebagai jembatan penghubung antara Arduino uno r3 dengan komputer, agar program dapat diisikan dari komputer kedalam rangkaian Arduino uno r3.

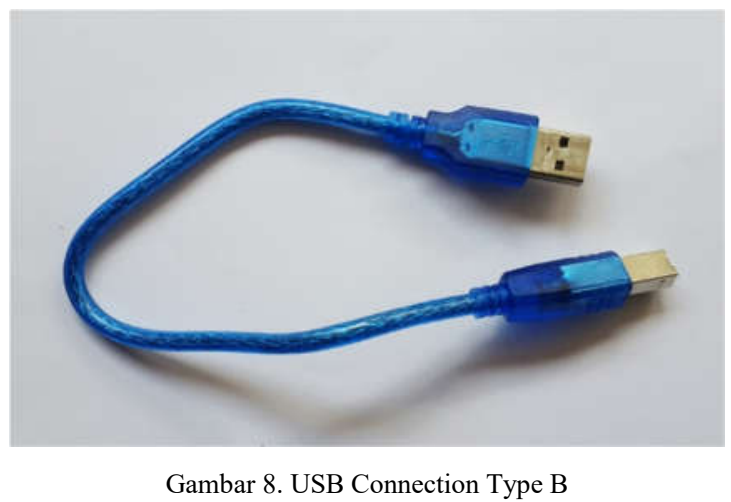

\section{Bread Board}

Bread board berfungsi sebagai tempat meletakkan rangkaian logika yang dibentuk sedemikian rupa agar mudah dalam penempatan alat rangkaian mikrokontroler seperti, LCD, Sensor Ultrasonik dan potensio dengan menggunakan penghubung kabel jumper.

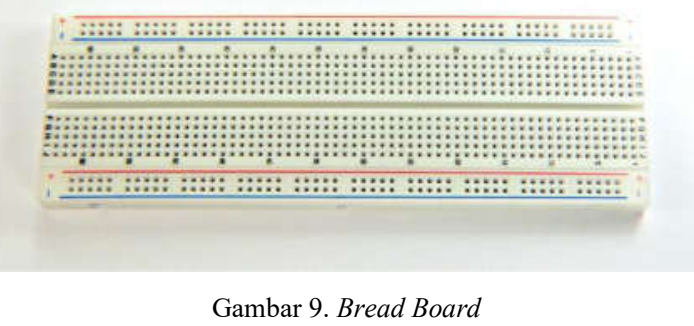

\section{Pin Header}

Untuk menghubungkan LCD dengan kabel jumper maka perlu pin header, jadi pin header di solder ke bagian LCD agar kabel jumper dapat dihubungkan ke LCD.

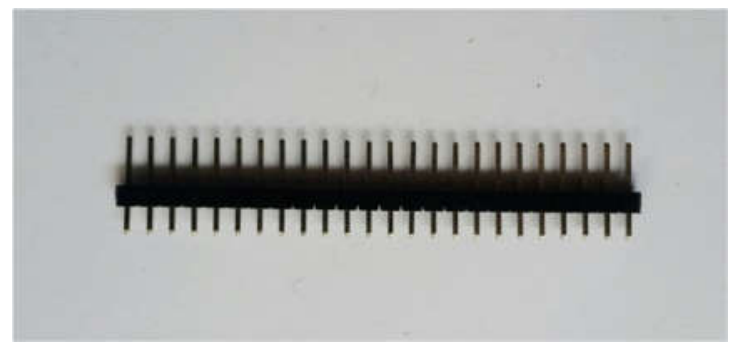

Gambar 10. Pin Header 
Jurnal Pseudocode, Volume VIII Nomor 1, Februari 2021, ISSN 2355-5920, e-ISSN 2655-1845

www.ejournal.unib.ac.id/index.php/pseudocode

\section{Potensiometer}

Potensiometer pada dasarnya berfungsi sebagai pembagi tegangan variabel. Potensio merupakan salah satu jenis Resistor yang Nilai Resistansinya dapat diatur sesuai dengan kebutuhan Rangkaian Elektronika ataupun kebutuhan pemakainya.

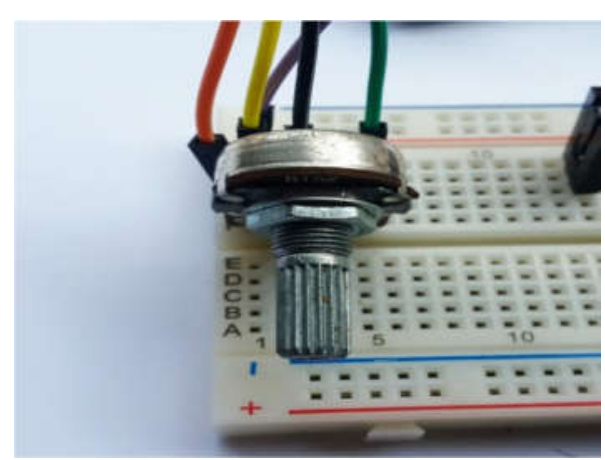

Gambar 11. Potensio

\section{Perangkat Lunak}

Perangkat lunak yang digunakan untuk Perancangan Alat Ukur Tinggi Badan Otomatis dengan Sensor Ultrasonik Srf-05 Berbasis Mikrokontroler adalah sebagai berikut:

\section{Software Arduino IDE}

Software Arduino IDE berfungsi sebagai text editor, sebagai verify coding untuk mengetahui apakah koding terdapat error dan sekaligus compiler yang akan di-upload kedalam memori mikrokontroler. Selain itu software Arduino juga berfungsi untuk menyambungkan komputer dan board Arduino dengan menggunakan koneksi USB.

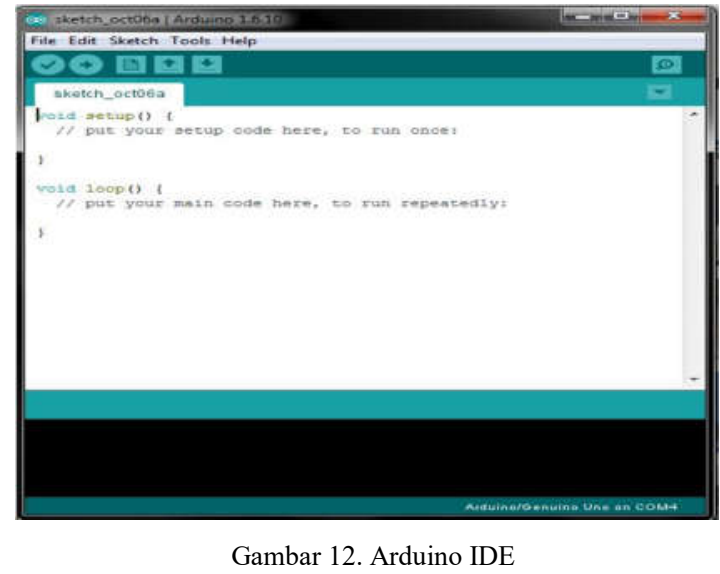

2. Rangkaian Alat

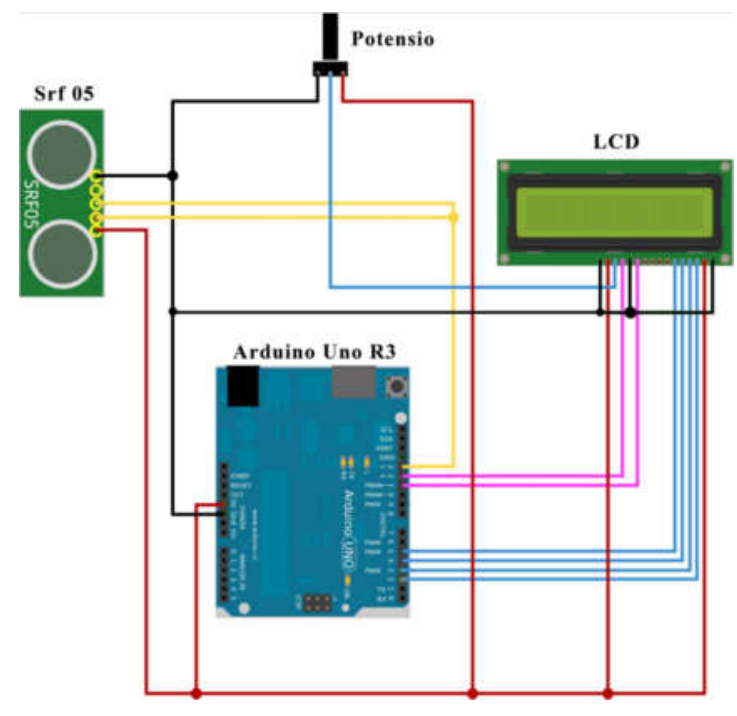

Gambar 13. Rangkaian Alat

3. Perancangan Perangkat Keras

Membuat gambar skema rancangan alat yang terdiri dari Arduino Uno R3, LCD, Potensio dan sensor SRF 05, dimana Arduino Uno R3 sebagai komponen utama dari rangkaian, LCD sebagai output dari pembacaan oleh sensor ultrasonik, Potensio sebagai pembagi tegangan ke LCD dan sensor SRF 05 ini adalah sebagai sensor jarak untuk mengukur tinggi badan secara otomatis. 
Jurnal Pseudocode, Volume VIII Nomor 1, Februari 2021, ISSN 2355-5920, e-ISSN 2655-1845 www.ejournal.unib.ac.id/index.php/pseudocode

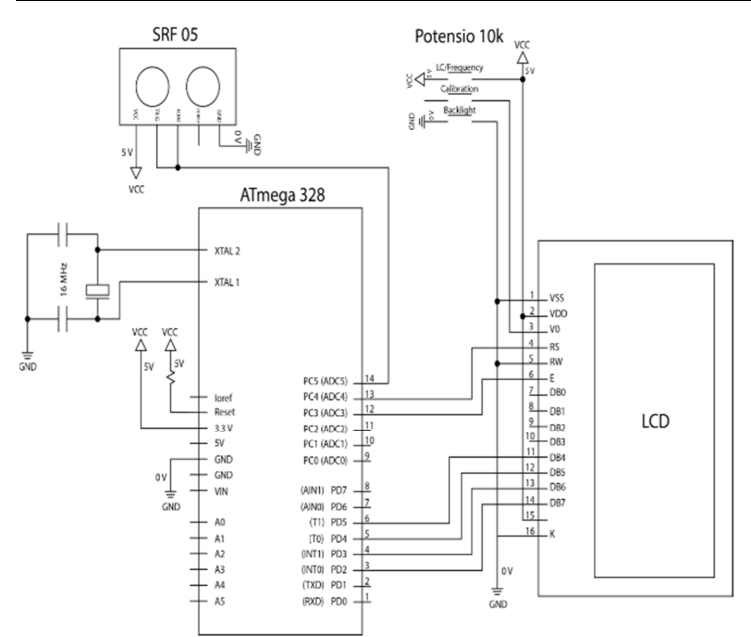

Gambar 14. Skema Perancangan Alat

\section{IMPLEMENTASI DAN PEMBAHASAN}

\section{A. Design Alat}

Design alat merupakan rangkaian dari prototype alat Pengukur Tinggi Badan Otomatis yang digunakan untuk mengimplementasikan alat tersebut nantinya. Design tersebut dibuat untuk memudahkan proses pengerjaan alat yang akan dibuat.

Bahan yang digunakan untuk membuat alat tersebut adalah dengan pipa sepanjang 2 meter sebagai tiang untuk pengukuran tinggi badan dan 1 buah kotak hitam untuk meletakkan peralatan elektronika serta 1 buah penyangga sensor Ultrasonik SRF-05. Untuk lebih detailnya dapat dilihat pada gambar 4.1 berikut.

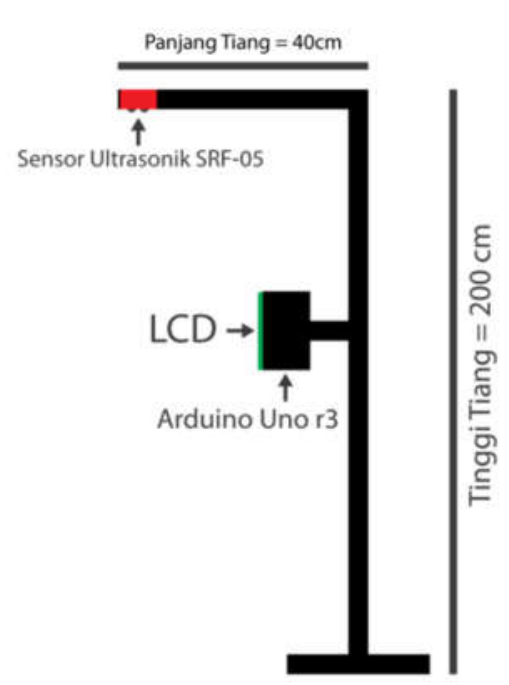

Gambar 15. Design Alat

\section{B. Hasil Akhir Alat}

Setelah semua peralatan yang digunakan selesai dikemas, maka hasil akhir dari Perancangan Alat Pengukur Tinggi Badan Otomatis dengan menggunakan Sensor Ultrasonik SRF-05 dan LCD sebagai Outputnya berbasis Arduino Uno r3 adalah sebagai berikut.

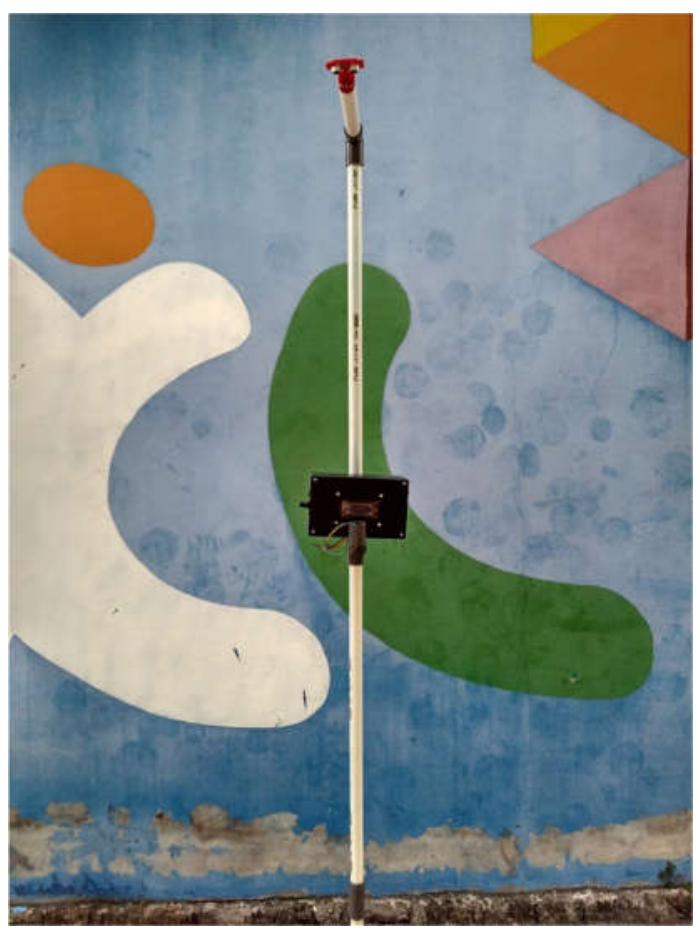

Gambar 16. Hasil Akhir Alat 
Jurnal Pseudocode, Volume VIII Nomor 1, Februari 2021, ISSN 2355-5920, e-ISSN 2655-1845 www.ejournal.unib.ac.id/index.php/pseudocode

\section{Pengujian Setelah Packaging}

Pengujian pada tahap ini sama saja dengan pengujian rangkaian mikrokontroller sebelumnya. Pengujian ini hanya mengecek fungsi-fungsi dari semua komponen yang sudah di-packaging dan disolder.

D. Pengujian Alat pada Objek (Black Box Tasting)

Pada tahap ini yang dilakukan adalah dengan Pengujian alat untuk mengukur tinggi badan seseorang untuk mengetahui apakah ada eror dengan alat yang di buat atau ada fungsi yang tidak berjalan sesuai harapan.

Tabel 1. Hasil Pengukuran Alat Pada Objek

\begin{tabular}{|c|c|c|}
\hline $\begin{array}{c}\text { Tinggi } \\
\text { Sebenarnya (CM) }\end{array}$ & $\begin{array}{c}\text { Pembacaan Tinggi } \\
\text { Pada Tampilan } \\
\text { LCD (CM) }\end{array}$ & $\begin{array}{c}\text { Eror Jarak } \\
\text { (CM) }\end{array}$ \\
\hline 165 & 166 & +1 \\
\hline 160 & 161 & +1 \\
\hline 169 & 171 & +2 \\
\hline 158 & 159 & +2 \\
\hline 168 & 170 & +1 \\
\hline 160 & 161 & +1 \\
\hline 170 & 171 & +2 \\
\hline 163 & 165 & +2 \\
\hline 159 & 161 & +2 \\
\hline
\end{tabular}

\section{KESIMPULAN}

Berdasarkan perancangan alat pengukur tinggi badan otomatis dengan menggunakan sensor ultrasonik srf-05 dan lcd sebagai outputnya berbasis arduino uno r3 dapat disimpulkan beberapa hal diantaranya sebagai berikut.

1. Perancangan alat pengukur tinggi badan otomatis dengan sensor ultrasonik srf- berbasis arduino uno r3 adalah dengan menggabungkan beberapa komponen elektronik seperti sensor ultrasonik srf-05, lcd, potensiometer, dan arduino uno r3 sebagai mikrokontroler.

2. Proses konfigurasi program ke dalam mikrokontroler arduino uno r3 mempengaruhi kinerja sistem sensor ultrasonik untuk mendeteksi tinggi badan sesorang dengan menghasilkan output di lcd.

3. Dari hasil pengujian terlihat bahwa hasil pembacaan tinggi pada tampilan lcd pada alat tidak tepat sama sekali dengan tinggi sebenarnya degan rata-rata kesalahan 1-2 CM.

\section{DAFTAR PUSTAKA}

[1] Nofyanty, Lylys. 2015. "Rancang Bangun Good Stick Pendeteksi Halangan Untuk Penyandang Tunanetra Berbasis Mikrokontroler Ta 2015/2016" Stmik Amikom

[2] Overa, Ari Tri. 2014. "Sistem Pemandu Kendaraan Untuk Parkir Paralel Secara Otomatis" UNIKOM

[3] Hukma, Saiyid. 2016. "Perancangan Alat Ukur Tinggi Air Pada Evaporimeter Untuk Monitoring Evaporasi Berbasis Mikrokontroler Stasiun BMKG Beringin Muara Teweh Kalimantan Tengah" Stmik Amikom

[4] Anonim. $2017 . \quad$ "Pengendali Mikro". https://id.wikipedia.org/wiki/Pengendali_mikro. 20 Desember 2016

[5] Simanjuntak, M G. 2013. "Perancangan Prototipe Smart Building berbasis Arduino UNO" USU

[6] Firdaus, Kacaribu Yunus. 2015 "Alat Ukur Sensor Ultrasonik Srf-05 Berbasis Mikrokontroler Pada Dinding Parkir" USU

[7] Andrianto, Heri. 2013. "Pemrograman mikrokontroler AVR Atmega16 menggunakan bahasa C". Bandung: Penerbit Informatika. hal 23 